\title{
Dilemma in diagnosing ovarian ectopic pregnancy
}

\author{
Harsha Rajpal*, Harvinder Kaur, Urvashi Miglani
}

Department of Obstetrics and Gynecology, Deen Dayal Upadhyay Hospital, New Delhi, India

Received: 29 December 2019

Revised: 23 January 2020

Accepted: 29 February 2020

\section{*Correspondence:}

Dr. Harsha Rajpal,

E-mail: drharsharajpalobgy@gmail.com

Copyright: () the author(s), publisher and licensee Medip Academy. This is an open-access article distributed under the terms of the Creative Commons Attribution Non-Commercial License, which permits unrestricted non-commercial use, distribution, and reproduction in any medium, provided the original work is properly cited.

\begin{abstract}
To study different presentation of ovarian ectopic pregnancy and its management. All the 4 patients of ovarian ectopic pregnancy presented in our hospital in the month of April 2019 were analysed. We reported 4 cases with a preoperative provisional diagnosis of ruptured ectopic pregnancy and intra-operative diagnosis of? ovarian ectopic pregnancy, however histopathological examination confirmed the diagnosis of ovarian ectopic pregnancy in only 2 of the cases while the other 2 were ruptured corpus luteal cyst. Wedge resection was performed in all 4 patients. Ovarian ectopic pregnancy is rare and can be missed radiologically and intra-operatively. Establishing early diagnosis is a challenge to the clinician, it commonly mimics tubal ectopic or ruptured corpus luteal cyst. Provisional diagnosis can be made intra-operatively when a hemorrhage mass is seen near the ovary with a normal fallopian tube but can be confirmed by histopathological examination. The chief goal of the treatment remains life-saving intervention by early diagnosis to reduce maternal mortality and morbidity.
\end{abstract}

Keywords: Corpus luteal cyst, Ectopic, Pregnancy

\section{INTRODUCTION}

Primary ovarian ectopic pregnancy is the implantation of gestation sac in the ovary. It is one of the rarest forms of ectopic pregnancy and accounts for $<3 \%$ of all ectopic pregnancies. ${ }^{1}$ Most of the times operated with a provisional diagnosis of either ruptured tubal ectopic pregnancy or haemorrhagic corpus luteal cyst. Though high-resolution transvaginal scan is a valuable tool but diagnosed in small percentages of cases only.

\section{CASE REPORT}

\section{Case 1}

A 25 years old G3P2L2 with previous 2 LSCS presented with 8 weeks of amenorrhea with spotting per vagina since 20 days. Patient was using IUCD as contraceptive. She had no history of PID or any other significant history. On examination she had no pallor, pulse of 96/min, blood pressure of $110 / 70 \mathrm{mmHg}$. Per abdomen was soft, no tenderness, rigidity or guarding. On vaginal examination there was fullness in left fornix. USG showed heterogeneous mass of $29 \times 30 \mathrm{~mm}$ in left adnexa with ring of fire with free fluid in pouch of Douglas and IUCD in lower segment. She underwent emergency laparotomy with dilatation and curettage. Intraoperatively left side ovary was ruptured with organized clot at ruptured site. $50 \mathrm{cc}$ of hemoperitoneum was present. Ovarian wedge resection with bilateral tubal ligation was done. Post-operative period was uneventful. Histopathological examination confirmed ovarian pregnancy (Figure 1).

\section{Case 2}

A 27-year-old G3P1L1E1 presented at 1 month of amenorrhea with complaints of pain lower abdomen and 
spotting per vagina for 1 day. She had history of exploratory laparotomy with left oophorectomy done 2 years back for left ruptured ectopic pregnancy. She did not have any past history of PID or IUCD insertion or any other significant history. On examination she had pallor, pulse of $104 / \mathrm{min}$ and blood pressure of $90 / 60$ $\mathrm{mmHg}$.

Per abdomen was soft, no guarding and rigidity. Vaginal examination showed normal uterine size with cervical motion tenderness and fullness and tenderness in right fornix. USG showed complex mass of $85 \times 46 \mathrm{~mm}$ in right adnexa with right ovary visualized separately. Moderate free fluid observed in pouch of Douglas. Emergency laparotomy revealed hemoperitoneum of 1 liter and right ruptured ovary for which ovarian wedge resection was done. Dilatation and curettage was also done. $3 \mathrm{PCV}$ were transfused post-operatively and rest of the period was uneventful. Histopathological examination of wedge resection showed ovarian tissue and corpus luteum and tissue obtained from D and $\mathrm{C}$ showed chorionic villi (Figure 2).

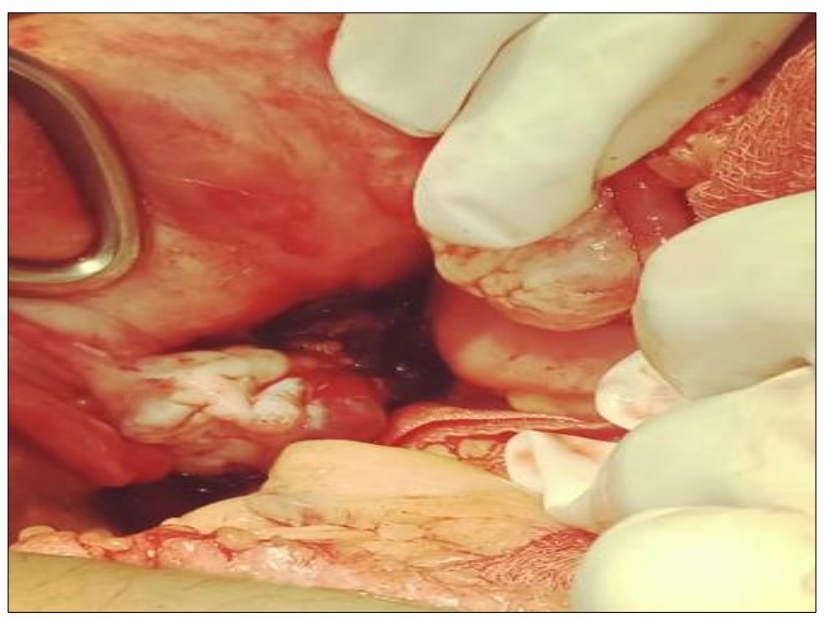

Figure 1: Left sided ruptured ovarian ectopic pregnancy.

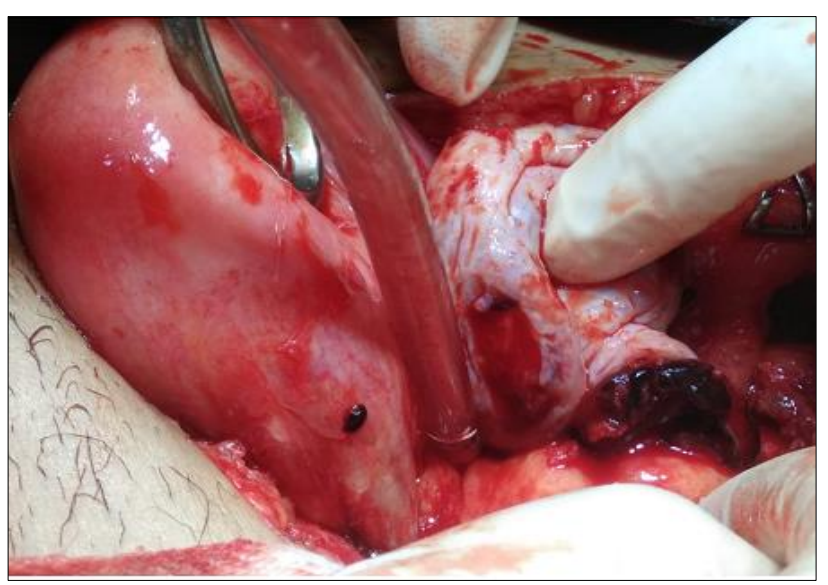

Figure 2: Enlarged and ruptured right ovarian ectopic pregnancy.

\section{Case 3}

A 25-year-old primigravida presented to us in shock with one and half month amenorrhea and excruciating abdominal pain and bleeding per vagina for past 10 days. Her previous menstrual history was regular with no significant medical or personal history. On examination her general condition was poor. she was pale with a pulse of $120 / \mathrm{min}$ and blood pressure of $80 / 60 \mathrm{mmHg}$. No guarding, tenderness or rigidity on per abdomen examination.

On per vaginal examination cervical motion tenderness was present along with left fornix fullness and tenderness. TVS showed left adnexal mass of $40 \times 50$ $\mathrm{mm}$ with endometrial thickness of $4.5 \mathrm{~mm}$ and fluid in pouch of Douglas. Emergency laparotomy with dilatation and curettage was performed with a pre-operative diagnosis of ruptured tubal ectopic pregnancy. Operative findings revealed ruptured left side ovarian pregnancy with hemoperitoneum of 1.25 liters. Wedge resection was done. Blood loss was managed with blood products. Patient was shifted to ICU as was not maintaining saturation, subsequently patient recovered and discharged. Histopathological examination of tissue from wedge resection revealed corpus luteal cyst and D amd C tissue showed chorionic villi (Figure 3).

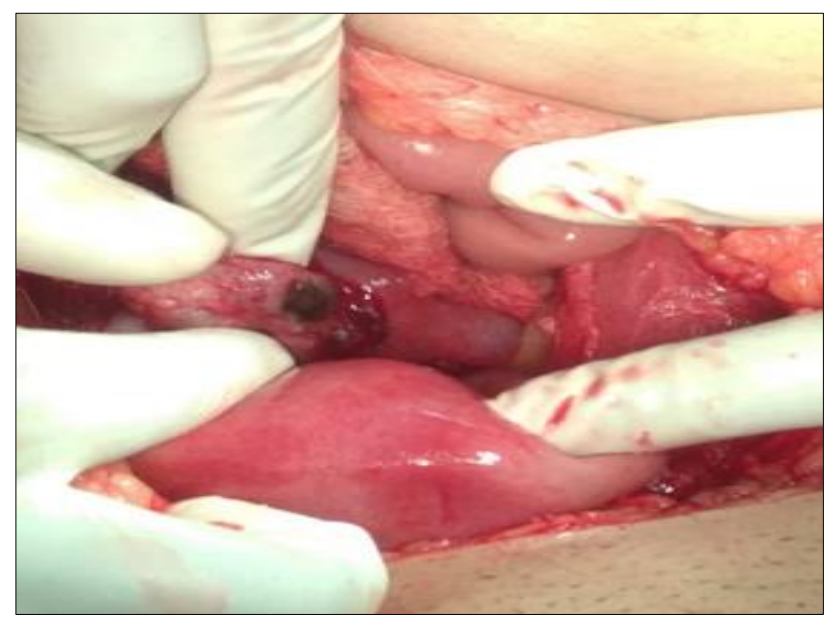

Figure 3: Left sided ruptured ectopic pregnancy with organised clot.

\section{Case 4}

A 25-year-old G2P1L1 presented to emergency department with one and half month amenorrhea, acute pain abdomen and spotting per vagina for 3 days. On examination she had no pallor, pulse of $88 / \mathrm{min}$, blood pressure of $110 / 70 \mathrm{mmHg}$. There was no tenderness, guarding or rigidity per abdomen. On per vaginal examination uterus was normal in size and a mass approx., $3 \times 2 \mathrm{~cm}$ in left adnexa and slight bleeding was present. TVS showed hyperechoic region of $21 \times 60 \mathrm{~mm}$ with evidence of gestational sac with cardiac activity. She underwent emergency laparotomy with dilatation and 
curettage. Intra operatively $200 \mathrm{ml}$ of hemoperitoneum was present, left ovary was enlarged and ruptured. Wedge resection was done for the same. Post-operative period was uneventful and patient was discharged in stable condition. Histopathological examination confirmed ovarian pregnancy (Figure 4).

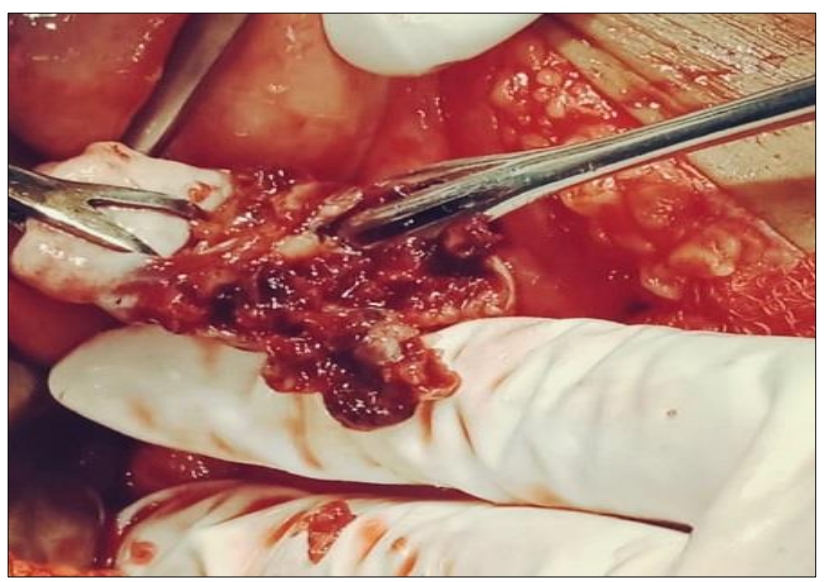

Figure 4: Intra-operative finding showing ruptured mass.

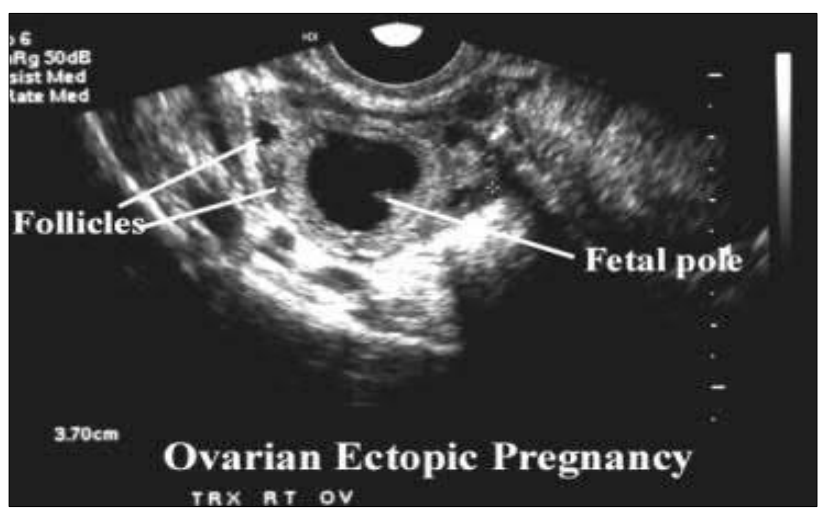

Figure 5: Transvaginal ultrasound showing right ovarian ectopic pregnancy and few ovarian follicles.

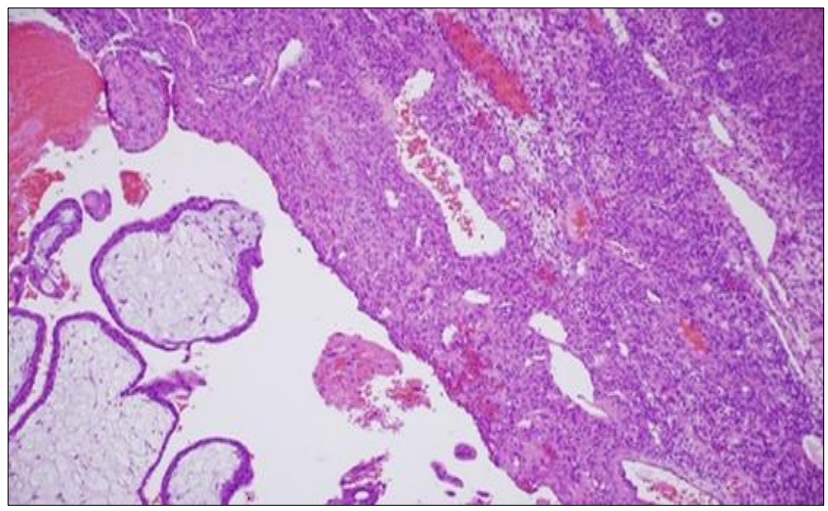

Figure 6: Histopathology slide (hematoxylin and eosin stain) showing chorionic villi amidst the hemorrhagic area in the ovarian tissue.

\section{Outcomes}

Authors reported 4 cases with a pre-operative provisional diagnosis of ruptured ectopic pregnancy and intra operative diagnosis of? Ovarian ectopic pregnancy, however histopathological examination confirmed the diagnosis of ovarian ectopic pregnancy in only 2 cases while the other 2 were ruptured corpus luteal cyst. Wedge resection was performed in all 4 patients.

\section{DISCUSSION}

Primary ovarian pregnancy is one of the rarest type of extrauterine pregnancy. There has been increase in incidence of ovarian pregnancy due to better diagnostic modalities, IUCD, ovulatory drugs, ART, Endometriosis and PID1. The cause is unknown and seems to be secondary to reflux of fertilized oocyte to the ovary. ${ }^{2}$ Other causes that have been suggested are interference in the release of ovum from ruptured follicle, malfunctioning of tubes and inflammatory thickening of ovarian tunica albugenia. Lehfeldt detected that IUCD prevent uterine implantation by $99.5 \%$ and tubal implantation by $95.5 \%$, however there is no preventive effect on ovarian implantation. Abdominal pain with a period of amenorrhea with or without vaginal bleeding is a common clinical symptom along with symptoms similar to tubal pregnancy including circulatory collapse. Many at times it is misdiagnosed clinically and radiologically as ruptured tubal ectopic pregnancy, corpus luteal cyst or hemorrhagic cyst.

Even it is difficult to differentiate ovarian pregnancy from ruptured corpus luteal cyst at time of surgery. Hallet in his study of 25 cases of ovarian pregnancy reported correct surgical diagnosis was made only in $28 \%$ of cases. Diagnosis can be made by high resolution transvaginal scan with classic description of wide echogenic ring with an internal echolucent area on the ovarian surface, presence of ovarian cortex including corpus luteum or follicles around the mass and echogenicity of ring is usually greater than that of the ovary itself. ${ }^{3}$ Other findings may be complex adnexal mass with or without fluid in pouch of Douglas and ovarian enlargement (Figure 5).

Spigelberg criteria is used for intra operative diagnosis: intact fallopian tube on the affected side, foetal sac must occupy the position of the ovary on the affected side, ovary connected to the uterus by ovarian ligament, ovarian tissue must be located in the sac wall, which is confirmed by histopathology (Figure 6). ${ }^{4}$

Little evidence is available regarding medical management of ovarian ectopic pregnancy using methotrexate, however some case reports have described successful treatment but has high treatment failure and risk of ovarian bleeding. ${ }^{5}$ Mainstay of management of ovarian pregnancy or corpus luteal cyst is surgical either conservative surgery or oophorectomy depending upon 
extent of tissue destruction. ${ }^{6}$ Conservative surgery like ovarian wedge resection should be preferred as patient usually belongs to reproductive age group and only a single case of recurrence has been reported in literature and involved contralateral ovary. ${ }^{7}$

\section{CONCLUSION}

Ovarian ectopic pregnancy is a rare entity and can be missed radiologically. Establishing early diagnosis is a challenge to the clinician. It commonly mimics tubal ectopic pregnancy, ruptured corpus luteum or haemorrhagic cyst. Intra operatively differentiation between ovarian pregnancy and ruptured corpus luteum is difficult. Provisional diagnosis can be made intraoperatively when a haemorrhagic mass is seen near the ovary with normal looking fallopian tubes but can only be confirmed by histopathology. Its management remains surgical despite in advancement of medical treatment. The chief goal of treatment remains life-saving interventions by early diagnosis to reduce maternal morbidity and mortality.

Funding: No funding sources Conflict of interest: None declared

Ethical approval: Not required

\section{REFERENCES}

1. Das S, Kalyani R, Lakshmi V, Kumar Harender ML. Ovarian pregnancy. Indian J Pathol Microbiol. 2008;51:37-8.
2. Kraemer B, Kraemer E, Guengoer E, Juhasz-Boess I, Solomayer EF, Wallwiener D, et al. Ovarian ectopic pregnancy: diagnosis, treatment correlation to Carnegie stage 16 and review based on a clinical case. Fertil Steril. 2009;92:392.e13-e15.

3. Ghi T, Banfi A, Marconi R, Iaco PD, Pilu G, Aloysio $\mathrm{DD}$, et al. Three-dimensional sonographic diagnosis of ovarian pregnancy. Ultrasound Obstet Gynecol. 2005;26:102-4.

4. Spigelberg O. Casusistik der ovarial sch wanger schaft. Arch Gynecol. 1878;13:73.

5. Birge O, Erkan MM, Ozbey EG, Arslan D. Medical management of ovarian ectopic pregnancy: a case report. J Med Case Rep. 2015;9(290):1-4.

6. Gaubert P, Dufour P, Devisme L, Massoni F, Querleu D. Grosses ovarienne. A Propos d'une observation. Presse MED. 1999;28:2103.

7. Riethmuller D, Sautier JL, Benoit S, Roth P, Schaal JP, Maillet R. Diagnostic echographique et traitement laparoscopique d'une Grossesse ovarienne. A Propos d'un cas et revue de la litterature. J Gynecol Obstet Biol Reprod. 1996;25:378-83.

Cite this article as: Rajpal H, Kaur H, Miglani U. Dilemma in diagnosing ovarian ectopic pregnancy. Int J Reprod Contracept Obstet Gynecol 2020;9:1296-9. 